\title{
O PROTETOR-RECEBEDOR NO DIREITO AMBIENTAL
}

COSTA, Dahyana Siman Carvalho da. Advogada, especialista em Direito da Economia e da Empresa pela FGV, mestre em Desenvolvimento Regional e Meio Ambiente pela Uniara e docente do Centro Universitário do Leste de Minas Gerais - Unileste/MG. End.: Rua Visconde de Mauá, 755, ap. 201, Cidade Nobre, Ipatinga/MG.

E-mail: dahyanasiman@yahoo.com.br.

\section{Resumo}

Para atingir o objetivo de preservar o meio ambiente existem diversos mecanismos legais já amplamente discutidos e efetivados. Contudo, a degradação ambiental continua crescendo. Então, para aprimorar a preservação do equilíbrio ambiental, surgem novas ferramentas que buscam propiciar a conservação ambiental, retribuindo, com uma compensação financeira, aquele que cumpre a legislação e presta serviços relevantes à melhoria do ambiente. Nesse sentido, o presente artigo faz uma breve análise do Direito Ambiental Brasileiro com seus princípios e instrumentos que visam à conservação e preservação do meio ambiente, propondo desenvolver e aprimorar a ideia do pagamento por serviços ambientais, também conhecido como protetor-recebedor, em complementação ao princípio do poluidor-pagador e usuário-pagador. O objetivo é discutir essa possibilidade no atual ordenamento jurídico brasileiro, mediante uma revisão da legislação brasileira e da bibliografia especializada, concluindo que benefícios financeiros podem ser concedidos àqueles que preservam o meio ambiente, como forma de incentivo e aprimoramento da Política Nacional do Meio Ambiente.

Palavras-chave: Preservação ambiental; Pagamento; Protetor-recebedor.

\section{Abstract}

To achieve the goal of preserving environment there are several legal mechanisms, which have already been widely discussed and established. However, environmental degradation continues to grow. So, to improve the preservation of environmental balance, there are new tools that aim to facilitate environmental conservation, returning, with a financial compensation, to those that respect law and provide relevant services to improve environment. In this sense, the present paper shows a brief analysis of the Brazilian Environmental Law with its principles and instruments aimed at the conservation and preservation of environment, proposing to develop and refine the idea of payment for environmental services, also known as the receiver-protector principle, complementing the polluter-pays and user-pays principles. The aim is to discuss this possibility in the current Brazilian law, based on a review of the Brazilian law and of the relevant literature. We concluded that financial benefits may be granted to those who preserve environment as a way of encouraging and improving the National Environmental Policy.

KEYwORDs: Environmental preservation; Payment; Receiver-protector. 


\section{INTRODUÇÃO}

O homem sempre fez uso dos recursos naturais como meio de sobrevivência, porém, inicialmente, essa utilização objetivava atender às necessidades de sua subsistência. Com o passar dos anos, em especial no século XIX, surgiram as indústrias e, a partir desse momento, o uso dos recursos ambientais intensificaramse de forma acelerada e irracional. Em busca do lucro a qualquer custo, passamos a degradar o ambiente.

Desde então, os problemas ambientais aumentaram e chegaram a proporções globais, fazendo com que vários países passassem a discutir formas de amenizar os impactos ambientais e preservar o meio ambiente natural.

No Brasil não é diferente, inclusive, a legislação ambiental tem avançado na busca de novos mecanismos para evitar a degradação ambiental e proteger o equilíbrio do meio ambiente.

A partir dessa preocupação com a degradação ambiental e da magnitude a que o assunto chegou, surgiu um novo ramo do Direito, o chamado Direito Ambiental, que se dedica exclusivamente a criar instrumentos legais para a proteção do meio ambiente, buscando o respeito, por parte do homem, ao ambiente.

Cumpre observar que já se reconhece o Meio Ambiente numa visão global, não somente como os recursos naturais, mas também como os recursos culturais, artificiais e do trabalho. De acordo com a Política Nacional do Meio Ambiente (Lei 6.938/81), o meio ambiente é o conjunto de condições, leis, influências e interações de ordem física, química e biológica, que permite, abriga e rege a vida em todas suas formas.

Assim, com esta visão ampla de Meio Ambiente, tem-se como importante identificar os problemas ambientais vivenciados pela sociedade, mostrando a todos a importância dos recursos ambientais e buscando novas soluções. Nesse sentido, destaca-se o papel da educação ambiental, que procura conduzir as pessoas a terem uma convivência harmoniosa com o meio ambiente e conscientizá-las das atividades antropogênicas, que prejudicam o meio em que vivemos, tentando, assim, alcançar o desenvolvimento sustentável, ou seja, o equilíbrio entre o crescimento econômico e a preservação do meio ambiente.

Contudo, a questão do meio ambiente envolve um grande leque de assuntos relacionados à sua proteção, conservação e recuperação. Na busca de instrumentos que pudessem ajudar a alcançar o desenvolvimento sustentável, surgiram vários mecanismos, como a definição de padrões de qualidade, o licenciamento ambiental, os estudos de avaliação prévia dos impactos ambientais, dentre outros tantos, com base fundamental na ideia do poluidor ou usuário-pagador, impondo o ônus da preservação ambiental ao empreendedor.

Os avanços na proteção ambiental, no entanto, não alcançaram os patamares desejados, verificando-se a necessidade de novos instrumentos para implementar a integral proteção do meio ambiente, com base numa ideia fundamental bem diferente, chamada de protetorrecebedor.

Surgem, então, os instrumentos de compensação financeira pela proteção ambiental, ou o pagamento por serviços ambientais, que podem ser de grande valia para a proteção do meio ambiente, em especial dos recursos hídricos, das florestas, do solo e da biodiversidade, que são reservas naturais finitas, devendo ser utilizadas de maneira racional.

Gratificar ou compensar financeiramente o protetor dos recursos ambientais pode ser um mecanismo eficiente para incentivar a proteção e, ao mesmo tempo, conscientizar as pessoas do papel que o homem deve assumir frente às questões ambientais para garantir a sua sobrevivência no planeta.

Atualmente já existem serviços ambientais que são pagos, como o programa Bolsa Verde, em Minas Gerais, e o ICMS Ecológico, em vários Estados brasileiros. Ambos concedem benefícios financeiros a fim de favorecer aquele que preserva o meio ambiente.

Contudo, esse é um ponto mais recente nas discussões ambientais, mas que se acredita ser de fundamental importância para o país avançar em suas políticas públicas de proteção ambiental.

\section{O Direito Ambiental}

De acordo com Milaré (2005), foi somente a partir 
da segunda metade do século XX que surgiu o relacionamento de interdependência entre as nações para a cooperação no que se diz respeito à preservação do Meio Ambiente.

Com todos os problemas ambientais enfrentados e a preocupação mundial com a degradação ambiental, Antunes (2006) afirma que uma das principais características do Direito Internacional do Meio Ambiente é uma enorme quantidade de Tratados, Convenções e Protocolos Internacionais, todos voltados para a proteção ambiental, sendo que, dentre esses, se destacam as três maiores conferências sobre o tema: a Conferência de 1972, a Rio-92 e a de Johanesburgo na África do Sul.

No final da década de 60, o crescimento econômico e a industrialização já estavam trazendo resultados desastrosos para o planeta e, com a preocupação pela degradação ambiental, a Suécia propôs à ONU a realização de uma conferência para discutir os assuntos ambientais que já alcançavam proporções globais. Foi assim que em ocorreu a Primeira Conferência Mundial sobre o Homem e o Meio Ambiente, realizada em 1972, em Estocolmo, na Suécia, com a participação de vários países.

De acordo com Milaré (2005), dessa Conferência surgiu um documento chamado de Declaração de Estocolmo, em que foram dispostos 26 princípios referentes ao comportamento e as responsabilidades dos países frente as questões ambientais, com intuito de nortear os processos decisórios, orientando a humanidade para a preservação e melhoria do ambiente humano.

Em 1992, na cidade do Rio de Janeiro, houve a Conferência das Nações Unidas sobre o Meio Ambiente e Desenvolvimento, que foi convocada com o fim de alertar os países para a necessidade de reverter o crescente processo de degradação do planeta.

Também conhecida como Cúpula da Terra, Eco92 e Rio-92, foi nessa conferência que se consagrou o conceito de desenvolvimento sustentável, o que contribuiu para a conscientização de que os danos ao meio ambiente eram, na maioria, de responsabilidade dos países desenvolvidos. Percebeu-se também a necessidade de os países em desenvolvimento receberem apoio financeiro e tecnológico para avançar na direção do desenvolvimento sustentável.

Os compromissos específicos adotados pela Conferência Rio-92 incluem duas convenções, uma sobre Mudança do Clima e outra sobre Biodiversidade, além de uma Declaração sobre Florestas. Aconferência aprovou documentos de objetivos mais abrangentes e de natureza política, como a Declaração do Rio e a Agenda 21.

Conforme Antunes (2006), a Agenda 21 é um conjunto de metas e objetivos que visou estabelecer orientações para a comunidade internacional durante o século XXI.

Após dez anos da Cúpula da Terra, os resultados esperados não foram alcançados. Dessa maneira, em 2002, em Johanesburgo, maior cidade da África do Sul, aconteceu o evento que ficou conhecido como Rio+10. Como objetivo principal, a conferência deveria rever as metas propostas pela Agenda $21 \mathrm{e}$ refletir sobre outros acordos e tratados.

Segundo Milaré (2005) a Conferência de Johanesburgo estabeleceu posições políticas e reafirmou os princípio e acordos adotados na Conferência de Estocolmo e na Rio 92. Um dos documentos resultantes da Rio+10 define as seguintes metas: erradicação da pobreza, mudança nos padrões insustentáveis de produção e consumo e proteção dos recursos naturais.

Neste contexto, ressalta-se que, no Brasil, somente a partir da década de 80 é que a legislação ambiental passou a desenvolver-se com maior consistência, devido aos reflexos da Conferência de Estocolmo de 1972, pois até então o conjunto de leis existentes não se preocupava em proteger o meio ambiente de forma global. (MILARÉ, 2005).

Nesse processo de consolidação das legislações voltadas diretamente à proteção do meio ambiente, Milaré (2005) destaca quatro acontecimentos importantes: o primeiro foi a edição da Lei 6.938, de 1981, que instituiu a Política Nacional do Meio Ambiente-PNMA; o segundo foi a Lei 7.347 de 1985, que disciplinou a ação civil pública como instrumento 
processual para a defesa do Meio Ambiente; o terceiro foi a promulgação, em 1988, da Constituição Federal; e, por último, a Lei 9.605 de 1998, que dispõe sobre as sanções penais e administrativas aplicadas às atividades lesivas ao Meio Ambiente.

A Constituição Federal de 1988 foi um marco para o Direito Ambiental brasileiro, trazendo de forma ampla e geral a imposição de proteção ao Meio Ambiente, pelo poder público e pela coletividade. No capítulo VI, em seu artigo 225, a Constituição considerou o meio ambiente como um bem de uso comum do povo e direito fundamental do cidadão.

Art.225. Todos têm direito ao meio ambiente ecologicamente equilibrado, bem de uso comum do povo e essencial à sadia qualidade de vida, impondo-se ao poder público e à coletividade o dever de defendê-lo e preservá-lo para as presentes e futuras gerações (BRASIL, 2001, p.150).

Contudo, dentre as leis infraconstitucionais, ganha destaque a Lei 6.938/81, que criou uma verdadeira Política Nacional do Meio Ambiente, definiu seus objetivos, princípios e mecanismos de atuação. Granziera (2009) diz que essa política refletiu a preocupação da sociedade brasileira em promover o desenvolvimento do país, garantindo a preservação dos recursos naturais e, com ela, importantes inovações foram introduzidas no direito brasileiro para adequar os institutos jurídicos às especificidades da política ambiental.

A Lei Federal 6.938, de 1981, para conquistar o objetivo proposto, isto é, preservar o patrimônio ambiental a fim de conservá-lo para as presentes e futuras gerações, cuidou também de criar os mecanismos de formulação e aplicação, ou seja, os instrumentos da Política Nacional do Meio Ambiente, que são os meios legais instituídos para que seus objetivos sejam concretizados, conforme apresentados no art. $9 .^{\circ}$ do diploma legal:

Art 9. ${ }^{\circ}$ - São instrumentos da Política Nacional do Meio Ambiente:

I - o estabelecimento de padrões de qualidade ambiental;

II - o zoneamento ambiental;

III - a avaliação de impactos ambientais;

IV - o licenciamento e a revisão de atividades efetiva ou potencialmente poluidoras;

$\mathrm{V}$ - os incentivos à produção e instalação de equipamentos e a criação ou absorção de tecnologia, voltados para a melhoria da qualidade ambiental;

VI - a criação de espaços territoriais especialmente protegidos pelo Poder Público federal, estadual e municipal, tais como áreas de proteção ambiental, de relevante interesse ecológico e reservas extrativistas;

VII - o sistema nacional de informações sobre o meio ambiente;

VIII - o Cadastro Técnico Federal de Atividades e Instrumentos de Defesa Ambiental;

IX - as penalidades disciplinares ou compensatórias ao não cumprimento das medidas necessárias à preservação ou correção da degradação ambiental;

$\mathrm{X}$ - a instituição do Relatório de Qualidade do Meio Ambiente, a ser divulgado anualmente pelo Instituto Brasileiro do Meio Ambiente e Recursos Naturais Renováveis - IBAMA;

XI - a garantia da prestação de informações relativas ao Meio Ambiente, obrigando-se o Poder Público a produzi-las, quando inexistentes;

XII - o Cadastro Técnico Federal de atividades potencialmente poluidoras e/ou utilizadoras dos recursos ambientais;

XIII - instrumentos econômicos, como concessão florestal, servidão ambiental, seguro ambiental e outros.

Esses instrumentos são essenciais para aplicação da lei e das diretrizes da política nacional do Meio Ambiente. Todos são importantes e devem ser efetivamente utilizados, em conjunto; contudo neste estudo se dará ênfase ao último instrumento da lista, que são os instrumentos econômicos, inserido posteriormente pela Lei 11.284 de 2006. 


\section{Princípios do Direito Ambiental}

De acordo com Antunes (2006), os princípios do Direito Ambiental podem ser implícitos ou explícitos. Enquanto os explícitos são aqueles que estão escrito em textos legais e na Constituição da República Federativa do Brasil, os implícitos são os que decorrem do sistema constitucional, mesmo não estando escritos. Ambos devem ser levados em conta pelo aplicador da ordem jurídica.

Segundo Machado (2006), os princípios são utilizados como alicerce do Direito e estão formando e orientando a geração e implementação do Direito Ambiental.

Muitos são os princípios de Direito Ambiental destacados pela doutrina; porém, neste estudo será feita uma breve análise de apenas alguns dos princípios apresentados, aqueles mais diretamente ligados ao tema da investigação proposta.

\section{Princípio do Desenvolvimento Sustentável}

Sustentabilidade quer dizer usufruir dos recursos naturais, mas ao mesmo tempo protegendo-os. Isso vale dizer que o homem tem o direito de usufruir dos recursos ambientais, mas com a obrigação de preservá-los.

Durante anos e anos ao longo da história, o homem aproveitou dos recursos ambientais sem se preocupar com as gerações futuras e com o equilíbrio do planeta. Como consequência, atualmente, tem-se o efeito estufa, a chuva ácida, a destruição da camada de ozônio, a poluição dos rios, mares e outros tantos problemas, que além de afetarem, diretamente, a natureza, também afetam o homem.

Dessa forma, a fim de alcançar o objetivo de preservar mesmo utilizando os recursos, a Agenda 21 de 1992 trouxe como meta a busca pelo respeito de todos os países a esse princípio tão importante para a continuidade da espécie humana e da biodiversidade, que é uma responsabilidade. É necessário ter como metas diminuir o desperdício e o consumo desordenado e parar de desrespeitar os recursos disponíveis, ou seja, é preciso ter um crescimento sustentável.

$\mathrm{Na}$ Comissão Mundial sobre o Meio Ambiente, e Desenvolvimento criada pelas Nações Unidas, surgiu a definição de Desenvolvimento Sustentável, sendo aquele capaz de suprir as necessidades da geração atual, sem comprometer a capacidade de atender às necessidades das futuras gerações, ou seja, é o desenvolvimento que não esgota os recursos naturais.

Segundo Farinha (2006), o desenvolvimento sustentado responde às necessidades do presente sem comprometer a capacidade das gerações futuras de responder às suas próprias necessidades. Sendo assim a proteção do meio ambiente é parte integrante do processo de desenvolvimento e não pode ser considerada de forma isolada.

Diante da proporção dos problemas ambientais atuais e da procura para preservar o que ainda restou, pode-se então afirmar que o desenvolvimento sustentável se tornou-se um desafio para a sociedade.

\section{Princípio do poluidor-pagador}

Segundo Milaré (2005), a Lei da Política Nacional do Meio Ambiente acolheu o princípio do poluidorpagador, estabelecendo como um de seus objetivos a imposição ao poluidor da obrigação de recuperar e/ ou indenizar os danos causados. De acordo com Antunes (2006), o princípio parte da constatação da escassez dos recursos ambientais e que o seu uso na produção e no consumo causam a sua redução e degradação.

Desse princípio se entende que é fundamental o repasse dos custos para aqueles que usufruirão do benefício econômico; então, cabe ao responsável do projeto arcar com as despesas do Estudo de Impacto Ambiental, das medidas mitigadoras propostas e da recuperação do dano ambiental, ou seja, o princípio obriga o poluidor a pagar pela poluição causada ou pela que vai causar (FARINHA, 2006).

Miláre (2005) diz que esse princípio não objetiva tolerar a poluição mediante um preço, nem se limitar apenas em compensar os danos causados, mas sim evitar o dano ao meio ambiente. Busca-se, portanto, imputar ao poluidor o custo social da poluição por ele gerada, responsabilizando-o pelo dano ecológico não somente sobre bens e pessoas, mas sobre toda a natureza. 
Logo, não se deve confundir esse princípio como licença para poluir, pois o custo gerado para o poluidor tem a função de punir, para que este crie a consciência de que o meio ambiente deve ser preservado, inclusive no processo de produção e desenvolvimento. Machado (2006) diz que o poluidor que paga, não paga para poluir; o pagamento representa uma punição e a obrigação de reparar o dano.

Conforme Farinha (2006), vários fatores recomendam que se obrigue o poluidor a restituir o dano, quando possível, pois existem várias dificuldades na reparação do dano ambiental, sendo muitas vezes impossível o retorno ao estado anterior. Assim, a reparação do dano por meio da compensação ambiental é muitas vezes a melhor saída, ficando a indenização em segundo plano, até porque quantificar os danos em matéria ambiental é uma equação financeira difícil e inadequada.

Em suma, o princípio do poluidor-pagador busca evitar a ocorrência do dano e caso ocorrido, visa a sua reparação ou correção, atribuindo ao poluidor o custo social da poluição gerada por ele, impondo-lhe o custo ambiental. $\mathrm{O}$ princípio obriga o poluidor a internalizar os custos ambientais da sua atividade e a pagar pela poluição que pode ser causada ou que já foi causada por sua atividade.

\section{Princípio do usuário-pagador}

Decorre da ideia do poluidor-pagador, mas o princípio do usuário-pagador é ainda mais amplo, vai além da figura do poluidor e impõe a todos os usuários dos recursos naturais a obrigação de pagar pelo uso, independentemente de ter ou não causado poluição.

A Lei 6.938/81, em seu art. $4 .^{\circ}$, leva em conta que os recursos ambientais são escassos, portanto, sua produção e consumo geram reflexos, ora resultando em sua degradação, ora resultando em sua escassez. Assim, ainda que não tenha causado poluição, o usuário do recurso ambiental deve suportar seus custos, evitando-se a escassez.

Ademais, o uso gratuito de um recurso ambiental gera um enriquecimento ilícito, pois o meio ambiente é um bem que pertence a todos; assim, se alguém está se beneficiando do uso de um recurso natural, deve pagar por este uso.

Desse princípio surge, por exemplo, a possibilidade de cobrança pelo uso da água, independentemente de sua poluição.

\section{O PROTETOR-RECEBEDOR}

Usufruir de um meio ambiente saudável é um direito de toda a coletividade. Contudo, no atual contexto global, em que os recursos naturais estão cada vez mais concentrados, devido à desigualdade social e econômica, e por causa da utilização irracional desses recursos, é necessário aplicar uma ideia de justiça ambiental que possa amenizar os impactos causados pelo homem à natureza.

Diante disso, observa-se que é cada vez mais necessária uma política ambiental que encontre uma forma de incentivar ações que induzam à preservação do planeta, pois percebe-se que, mesmo com uma legislação ambiental intensa que prevê diversas sanções ao seu descumprimento, ainda estamos longe de alcançar os patamares de preservação desejados.

Logo, conclui-se que é preciso desenvolver novos instrumentos para minimizar a degradação ambiental e manter o equilíbrio ecológico, ou seja, alcançar o desenvolvimento sustentável. Assim, deve-se fazer uso dos princípios ambientais já existentes e passar a aceitar como princípio, ou base fundamental da política pública, a ideia do protetor-recebedor, que surgiu com base na questão da compensação financeira por serviços ambientais.

Como conceito, esse princípio advém da ideia de que uma pessoa que protege uma área ambiental deve receber uma compensação financeira como incentivo, deixando assim de explorar seus recursos e passar a preservá-los. É uma forma de estimular a preservação e pagar pelos serviços ambientais prestados.

Ora, se o meio ambiente é direito difuso, que pertence a todos ao mesmo tempo, ninguém pode degradá-lo, nem dele se apropriar indistintamente, sob pena de se aplicar o princípio do poluidor-pagador ou o princípio do usuário-pagador, respectivamente, impondo-se a internalização dos custos ambientais. 
Na mesma linha de raciocínio, não se pode impor a algumas poucas pessoas todo o ônus de cuidar da preservação ambiental em benefício de toda a coletividade, devendo-se então aplicar o princípio do protetor-recebedor e compensar o protetor, seja em pecúnia, seja com incentivos fiscais, pelo serviço prestado.

Exemplificando, tem-se o pequeno produtor rural, que depende da exploração das suas terras para manter o sustento da família; contudo, por imposição legal, terá de manter em sua propriedade a reserva legal e respeitar as eventuais áreas de preservação permanente. Dessa forma, ele está fazendo um bem para toda a coletividade, mantendo essas áreas preservadas, mas está sofrendo um grande ônus, tendo diminuída sua renda.

Nesse caso, os custos não devem ser suportados exclusivamente pelos proprietários rurais, ao contrário, devem ser socializados. Assim, o protetor deve receber uma compensação pelos serviços ambientais prestados e tanto a sociedade quanto a natureza levariam vantagem, pois a sobrevivência humana e de todas as outras espécies dependem diretamente de um meio ambiente saudável.

Como tudo o que existe no mundo tem como base ou matéria-prima a utilização dos recursos naturais, logo o meio ambiente possui valor econômico, tornando justa a compensação financeira pela sua proteção, preservação e serviços prestados. Da mesma maneira que quem polui tem que pagar, quem preserva deve receber.

Como no nosso atual mundo capitalista muitas coisas só funcionam se houver um lucro econômico nas ações realizadas, a ideia do protetor-recebedor sugere uma compensação financeira aos protetores. Importante frisar que, para aplicação do protetorrecebedor, não é necessário que o benefício seja em dinheiro: pode constituir-se de isenções fiscais, por exemplo.

Contudo, o Instituto Socioambiental - ISA em publicação recente, traz uma indagação bastante interessante: é pagando que se preserva? Seria possível aplicar esse mecanismo da compensação financeira na sociedade como uma política pública, aceita pelo Poder Público?

De acordo com Altmann (2008), no Plano Legislativo há projetos de Lei no Congresso Nacional que visam à preservação da natureza seguida de uma compensação financeira. São eles: PL 60/2003; PL 144/2003 e PL 4.160/2004:

PL 60/2003 - Cria o Programa Nacional de Reservas para a Preservação Ambiental e dá outras providências.

PL 144/2003 - Institui compensação financeira com vistas à proteção e recuperação ambientais, cria o Bônus de Proteção Ambiental - BPA e dá outras providências.

PL 4.160/2004 - Prevê compensação financeira aos pequenos proprietários rurais que mantenham áreas de preservação permanente com cobertura vegetal nativa e dá outras providências.

Neste contexto, observa-se o interesse em aplicar $o$ incentivo financeiro àqueles que preservarem o meio ambiente. Porém, inicialmente, os dois primeiros projetos de lei foram rejeitados, enquanto o terceiro se entendeu como pertinente, devido às dificuldades econômicas enfrentadas pelos pequenos agricultores e, em 2005, a Comissão de Meio Ambiente e Desenvolvimento Sustentável aprovou o projeto, tendo como argumento a falta de êxito no cumprimento da legislação ambiental, mesmo esta sendo bastante rígida. No entanto, em 2006, o projeto foi rejeitado pela Comissão de Finanças e Tributação da Câmara dos Deputados, com o argumento de que não atende às exigências da Lei de Responsabilidade Fiscal e não indica as compensações exigidas. Por conseguinte, em 2007, os projetos de lei foram arquivados (ALTMANN, 2008).

Contudo, é importante frisar que já existem alguns instrumentos que põem em prática a ideia do protetorrecebedor, mas ela ainda não é reconhecida amplamente pelo Direito Ambiental; trata-se de um assunto novo, que precisa ser mais bem trabalhado, discutindo-se os meios para sua aplicação. 


\section{Pagamento por serviços ambientais}

Além da ideia encerrada pelo princípio do poluidorpagador e do usuário-pagador, de impor o ônus do custo da poluição ou da utilização em grande escala dos recursos naturais aos verdadeiros responsáveis, que devem internalizar os custos ambientais de sua atividade, surge a ideia de, por outro lado, compensar financeiramente aqueles que protegem o meio ambiente.

Atualmente já se fala em tributação ambiental ou direito tributário ambiental, que diz respeito ao financiamento da tutela ao meio ambiente, ou seja, as finanças públicas e a legislação tributária devem relacionar-se à proteção do meio ambiente, de forma que o Poder Público possa influenciar com ações de fiscalização e também com financiamento de projetos ambientais e ações de defesa do meio ambiente (FERNANDES, 2008).

Assim, o pagamento por serviços ambientais é um instrumento econômico ambiental, a fim de conservar a natureza a partir de benefícios financeiros para as pessoas que a protegem. Envolve vários instrumentos legais, como programas de incentivos fiscais - a isenção de Imposto Territorial Rural - ITR para áreas de Reserva Legal, programas de distribuição de mudas e apoio técnico para recuperação de Áreas de Preservação Permanente, entre outros. Internacionalmente, pode-se citar o mercado de créditos de carbono, implementado pelo Protocolo de Kyoto.

A intenção é ser este mais um mecanismo para alcançar a preservação ambiental, incentivando a procura da população por proteger o meio ambiente, seja pela conscientização, seja por sentir-se gratificado e receber algo em troca pela proteção ambiental.

Paim (2010) afirma que existem diversos projetos de lei (PL) no Congresso Nacional relacionados especificamente ao pagamento por serviços ambientais. São o PL 792/2007; PL 1.190/2007; PL 5.487/2009; PL 6.204/2009.

PL 792/2007 - Dispõe sobre a definição de serviços ambientais e dá outras providências PL 1.190/2007 - Cria o Programa Nacional de Compensação por Serviços Ambientais -
Programa Bolsa Verde, destinado à transferência de renda aos agricultores familiares, com condicionalidades.

PL 5.487/2009 - Institui a Política Nacional dos Serviços Ambientais, o Programa Federal de Pagamento por Serviços Ambientais, estabelece formas de controle e financiamento desse Programa, e dá outras providências.

PL 6.204/2009 - Altera os arts. 3. ${ }^{\circ}$ e $5 .^{\circ}$ da Lei n. ${ }^{\circ} 7.797$, de 10 de julho de 1989, que dispõe sobre o Fundo Nacional do Meio Ambiente.

Dessa maneira, percebe-se a importância da ideia do pagamento por serviços ambientais, visto que é uma forma de tentar atingir um maior cumprimento da legislação ambiental a partir de benefícios econômicos àqueles que favorecerem a natureza.

Como exemplo de incentivos pelo pagamento por serviços ambientais no Brasil, tem-se o Programa de Desenvolvimento Socioambiental da Produção Familiar - Proambiente, que oferece um terço do salário mínimo a agricultores e pecuaristas que utilizam práticas menos impactantes em sua produção. Outro exemplo é a isenção fiscal para Reservas Particulares do Patrimônio Natural, que exonera os proprietários que a possuem de pagar o ITR.

Assim, a iniciativa de pagamento ou incentivos fiscais pelos serviços ambientais são na prática formas de aplicação da ideia do protetor-recebedor, que pode auxiliar na política pública de preservação do meio ambiente.

\section{ICMS Ecológico}

O Imposto sobre Circulação de Mercadorias e Serviços - ICMS Ecológico é um dos maiores exemplos no Brasil de aplicação da ideia do protetorrecebedor. O ICMS ecológico é praticado em vários estados da federação, sendo, em resumo, um pagamento por serviços ambientais que o Estado faz àqueles municípios que preservam o meio ambiente.

O ICMS Ecológico é na verdade um incentivo fiscal, umrepasse financeiro aos municípios que possuem ações de preservação do meio ambiente (SOUZA, 2010). 
O ICMS é um imposto recolhido pelo Estado, mas que obrigatoriamente deve ser repartido com os municípios. De acordo com Faria (2009), a Constituição Federal determina em seu art. 158, parágrafo único, inciso II, que $25 \%$ do ICMS arrecadado pelo Estado sejam repassados aos municípios. Desses $25 \%, 3 / 4$ ou $75 \%$ devem ser distribuídos aos municípios na proporção do valor adicionado fiscal (VAF) e os outros $1 / 4$ ou $25 \%$, de acordo com o que dispuser a lei estadual.

Nesse contexto, conclui-se que os Estados brasileiros repassam, por lei, $25 \%$ da arrecadação do ICMS para os municípios; contudo, até $1 / 4$ desse valor será distribuído por critérios estabelecidos pelo próprio Estado, daí surgiu a ideia de se acrescer, nas leis estaduais, dentre os critérios para o repasse, questões relacionadas à preservação ambiental, como forma de incentivar os municípios a desenvolver projetos ambientais.

Dessa forma, o município que mantémáreas verdes preservadas, incentiva projetos de preservação ambiental, possuem saneamento básico, dentre outros, conforme dispuser a lei estadual, receberá uma parcela ainda maior do repasse do ICMS e, ao contrário, os municípios que não desenvolveremmelhorias ambientais e não tiverem áreas preservadas, receberão menos.

Segundo Souza (2010), esse repasse financeiro pelos Estados com critérios ambientais foi criado inicialmente pelo Paraná, em 1991. Depois outros Estados da federação, como São Paulo, Minas Gerais, Rio de Janeiro, Pernambuco, Mato Grosso, Mato Grosso do Sul, Amapá, Rio Grande do Sul, Tocantins, Acre, Ceará e Rondônia, aderiram à ideia.

O percentual do ICMS ecológico repassado não é necessariamente o mesmo em todos os Estados; contudo, foi igualmente idealizado como alternativa para estimular ações ambientais no âmbito dos municípios. Dessa forma, o ICMS Ecológico representa uma ação na luta por uma melhor qualidade de vida e é um estímulo para que os municípios continuem e/ou criem áreas de proteção ambiental.

Como se trata de um mecanismo fiscal que não mexe no bolso do contribuinte, pois diz respeito ao repasse obrigatório de parte dos valores do ICMS recolhidos pelos Estados, o ICMS Ecológico é bem aceito e passa a ser um dos critérios para o repasse desses valores, premiando os municípios que possuem, por exemplo, Unidades de Conservação e áreas de mananciais.

\section{Bolsa Verde}

Outro exemplo da aplicação da ideia do protetorreceber, ou do pagamento por serviços ambientais, é o programa Bolsa Verde do governo do Estado de Minas Gerais, instituído pela Lei Estadual 17.727, de 13 de agosto de 2008, que se baseia na ideia de que quem proteger um bem natural em benefício da comunidade receberá uma compensação financeira como incentivo à prestação de serviço de proteção ambiental, assim dispondo:

Art.1. ${ }^{\circ} \mathrm{O}$ Estado concederá incentivo financeiro a proprietários e posseiros rurais, sob a denominação de Bolsa Verde, nos termos desta Lei, para identificação, recuperação, preservação e conservação de:

I - áreas necessárias à proteção das formações ciliares e à recarga de aqüíferos; e

II - áreas necessárias à proteção da biodiversidade e ecossistemas especialmente sensíveis, conforme dispuser o regulamento.

O programa tem como público-alvo os proprietários e posseiros de área rural que já preservam ou que se comprometem a recuperar a vegetação de origem nativa em suas propriedades ou posses, priorizando agricultores familiares e pequenos produtores rurais, que receberão uma quantia paga pelo governo para preservar o meio ambiente.

O principal objetivo é preservar a cobertura vegetal nativa em Minas Gerais, visando à conservação e recuperação ambiental, além de incentivar os proprietários rurais a preservar e recuperar áreas de proteção, como as matas ciliares, nascentes, aquíferos, etc. O projeto prevê duas modalidades: a manutenção, em que há uma remuneração pelo serviço prestado ao 
meio ambiente, com a manutenção da vegetação nativa existente; e a recuperação da cobertura vegetal nativa, em que há menor recurso financeiro, mas com repasse de insumos para os beneficiados restaurarem, recomporem ou recuperarem a área com espécies nativas.

A verba a ser utilizada pelo Bolsa Verde virá, principalmente, do dinheiro proveniente de multas por descumprimento da lei ambiental e também do Fundo de Recuperação, Proteção e Desenvolvimento Sustentável das Bacias Hidrográficas do Estado de Minas Gerais.

Serão beneficiados pela Bolsa Verde os proprietários que recuperarem, preservarem e conservarem Áreas de Preservação Permanente (APP) como as necessárias à proteção das formações ciliares ao longo de cursos d'água, à recarga de aquíferos, à proteção da biodiversidade e ecossistemas especialmente sensíveis, bem como os que possuem Reserva Legal (RL).

Iinteressante frisar que esse incentivo financeiro é proporcional à dimensão da área preservada; assim, quem preservar mais, receberá mais. Portanto, o proprietário que tiver mais do que a legislação estabelece em relação à Área de Preservação Permanente (APP) e Reserva Legal (RL) recebe mais, mas quem cupre somente o que a lei exige tambémé beneficiado, porém com um valor inferior. $O$ produtor rural que não possui essas áreas preservadas recebe insumos e apoio técnico, mas para receber o benefício deve fazer um projeto de recuperação como condição para recebê-lo.

Outras informações sobre o programa podem ser encontradas no Manual de Procedimentos no site do Instituto Estadual de Florestas - IEF do governo de Minas Gerais, onde também estão os formulários para solicitações, necessários para participar do projeto. O projeto é um instrumento de aplicação do protetorrecebedor, ou seja, aquele que proteger uma área com características ambientais relevantes, receberá um incentivo financeiro.

Além de Minas Gerais existem programas similares em outros estados, fundamentados na mesma ideia, como no estado do Amazonas e do Espírito Santo.

O Bolsa Floresta, que é no Estado do Amazonas, é um programa voltado para famílias que vivem em Unidades de Conservação Estaduais há, no mínimo, dois anos. Já no Espírito Santo com o projeto Produtores de Água, os proprietários rurais que prestam serviços ambientais, como conservação e restauração florestal para a melhoria da qualidade da água, passam a receber benefícios financeiros.

Existe também a Lei Chico Mendes (Lei Estadual n. ${ }^{\circ}$ 1.277/89), no Acre, que oferece um subsídio econômico aos produtores de borracha por serviços ambientais prestados. Aideia de todos esses programas é a mesma do Bolsa Verde, pois o benefício recebido é financeiro em contraprestação a um serviço ambiental.

A remuneração pelos serviços ambientais prestados como de preservação e conservação é concebida como uma maneira de incentivar as pessoas a cumprir as normas ambientais e tentar amenizar os efeitos da atividade humana no meio ambiente.

\section{CONSIDERAÇões Finais}

Atualmente, devido à exploração irracional dos recursos naturais, e pelo fato de estes serem finitos, fica cada vez mais evidente o problema ambiental pelo qual o mundo está passando. Nesse contexto, surgem a cada momento novas ferramentas legais para que a proteção do meio ambiente seja feita, com intuito de conservar o que resta do ambiente natural, além de buscar sua recuperação.

Assim, surgiu a ideia do protetor-recebedor, em que um agente público ou privado que proteja um bem natural em benfício da comunidade deve receber uma compensação financeira como incentivo pelo serviço de proteção ambiental prestado, ou seja, é remunerar quem preservar a natureza.

A compensação financeira pela proteção ambiental pode ser entendida como um modelo de gestão ambiental, necessária para conservar o meio ambiente e protegê-lo da melhor maneira possível, ao criar mecanismos em que a sociedade possa usufruir do meio ambiente sem maiores impactos.

Ao aplicar o princípio do protetor-recebedor, tanto 
a sociedade quanto a natureza levariam vantagem, pois a sobrevivência humana e de todas as outras espécies dependem diretamente de um meio ambiente saudável e ainda servirá como justiça àqueles que prestam serviços ambientais a sociedade sem receber nada.

Apesar de não ser ainda reconhecido como um efetivo princípio de Direito Ambiental, já existem previsões para o pagamento por serviços ambientais na legislação. Muitas leis atuais trazem como instrumentos de proteção ambiental a ideia nele embutida, por exemplo, o ICMS ecológico e o Bolsa Verde. Aideia ainda está sendo implementada de forma esparsa, por iniciativas isoladas, mas tende a crescer.

Nesse sentido, entende-se que a ideia da compensação financeira deva ser aplicada em conjunto e de forma integrada com os outros instrumentos de proteção ambiental existentes. Assim, não se mostra como a solução para os problemais ambientais; contudo, é mais uma forma de se buscar a preservação ambiental.

A cada dia que passa o ambiente vai ficando ainda mais degradado, devido à falta de informação por parte da sociedade e desconhecimento ou descumprimento da legislação ambiental.

Dessa forma, é importante criar novas maneiras de incentivar a proteção ambiental aplicando a ideia do protetor-recebedor, mas é importante ressaltar que o lucro de preservar deve ser maior que o de produzir algo que poderia prejudicar o meio ambiente, lembrando que não há a intenção de cessar ou proibir qualquer atividade produtiva; a ideia é aumentar a extensão de áreas preservadas.

Considera-se que compensar financeiramente quem preserva é uma forma de atingir o objetivo de manter equilibrado o meio ambiente, essencial à qualidade de vida, conforme ressaltado pelo artigo 225 da Constituição Federal.

O que se entende é que o pagamento por serviços ambientais, ou seja, o princípio do protetor-recebedor, ao criar instrumentos econômicos alternativos, pode ajudar nessa verdadeira batalha e deve ser empregado da mesma maneira que os demais, em complementação à efetiva proteção do meio ambiente.

\section{REFERÊNCIAS}

ALTMANN, Alexandre. A compensação financeira pela preservação e recuperação da mata ciliar como instrumento de gestão ambiental. Revista de

Direito Ambiental, São Paulo, v.49, n. 13, p.11, jan/mar. 2008.

ANTUNES, Paulo de Bessa. Direito ambiental. 9. ed. Rio de Janeiro: Lumen Juris, 2006, 988 p.

\section{BRASIL. Constituição (1988). Constituição da}

República Federativa do Brasil: promulgada em 5 de outubro de 1988. Organização do texto: Cláudio Brandão de Oliveira. 10. ed. Rio de Janeiro: DP\&A, 2001.348 p.

\section{Lei Federal n. 6.938 de 31 de agosto}

de 1981. Dispõe sobre a Política Nacional do Meio Ambiente, seus fins e mecanismos de formulação e aplicação, e dá outras providências. Presidência da República Federativa do Brasil, Brasília, DF. Disponível em: < http://www.planalto.gov.br/ ccivil_03/Leis/L6938.htm.> Acesso em: 08 set. 2010 .

\section{Projeto de Lei n. ${ }^{\circ} 60$ de 18 de}

fevereiro de 2003. Cria o Programa Nacional de Reservas para a Preservação Ambiental e dá outras providências. Câmara dos Deputados, Brasília, DF. Disponível em: <http://www.camara.gov.br/internet/ sileg/Prop_Detalhe .asp?id=104467>. Acesso em: 26 out. 2010.

\section{. Projeto de Lei n. ${ }^{\circ} 144$ de 21 de}

fevereiro de 2003. Institui compensação financeira com vistas à proteção e recuperação ambientais, cria o Bônus de Proteção Ambiental BPA e dá outras providências. Câmara dos Deputados, Brasília, DF. Disponível em: <http:// www.camara.gov.br/internet/sileg/

Prop_Detalhe.asp?id=104903>. Acesso em: 26 out. 2010. 
. Projeto de Lei n. ${ }^{\circ} 792$ de 19 de abril

de 2007. Dispõe sobre a definição de serviços ambientais e dá outras providências. Câmara dos Deputados, Brasília, DF. Disponível em: <http:// www.camara.gov.br/internet/sileg/ Prop_Detalhe.asp?id=348783 >. Acesso em: 26 out. 2010.

\section{Projeto de Lei n. ${ }^{\circ} 1.190$ de 29 de}

maio de 2007. Cria o Programa Nacional de Compensação por Serviços Ambientais - Programa Bolsa Verde, destinado à transferência de renda aos agricultores familiares, com condicionalidades.

Câmara dos Deputados, Brasília, DF. Disponível em: <http://www.camara.gov.br/internet/sileg/ Prop_Detalhe.asp?id=353415> . Acesso em: 26 out. 2010.

. Projeto de Lei n. ${ }^{\circ} 5.487$ de 24 de junho

de 2009. Institui a Política Nacional dos Serviços Ambientais, o Programa Federal de Pagamento por Serviços Ambientais, estabelece formas de controle e financiamento desse Programa, e dá outras providências. Câmara dos Deputados, Brasília, DF. Disponível em: <http://www.camara.gov.br/internet/ sileg/Prop_Detalhe.asp?id=439941 >. Acesso em: 26 out. 2010.

Projeto de Lei n. ${ }^{\circ} 6.204$ de 13 de

outubro de 2009. Altera os arts. $3 .^{\circ}$ e $5 .^{\circ}$ da Lei n. ${ }^{\circ}$ 7.797, de 10 de julho de 1989, que dispõe sobre o Fundo Nacional do Meio Ambiente. Câmara dos Deputados, Brasília, DF. Disponível em: <http:// www. camara.gov.br/internet/sileg/ Prop_Detalhe. asp? $\mathrm{id}=454802>$. Acesso em: 26 out. 2010.

CONFERÊNCIA das Nações Unidas sobre Meio Ambiente e Desenvolvimento-ECO-92. Disponível em: <http://ambientes.ambientebrasil.com.br/gestao/ artigos/conferencia_das_

nacoes_unidas_sobre_meio_ambiente_e_desenvolvimento__eco-92.html>. Acesso em: 20 set. 2010.
CONFERÊNCIA de Estocolmo. Disponível em: $<$ http://pt.wikipedia.org/wiki/Confer\% C3\%AAncia_de_Estocolmo>.Acesso em: 17 set. 2010.

FARINHA, Renato. Direito ambiental. 1. ed. São Paulo: CL EDIJUR, 2006. 195 p.

FARIA, Caroline. ICMS Ecológico. Disponível em: $<$ http://www.infoescola.com/ecologia/ icmsecologico/>. Acesso em: 27 jun. 2010.

FERNANDES, Edison Carlos. Financiamento público da tutela do meio ambiente. In: ARAÚJO, Gisele Ferreira de (Org.) Direito ambiental. São Paulo: Atlas, 2006. 193 p.

GRAZIERA, Maria Luiza Machado. Direito ambiental. São Paulo: Atlas, 2009. 666 p.

\section{INSTITUTO ESTADUAL DE FLORESTA.}

Bolsa Verde Manual de Procedimentos. Disponível em: <http://www.ief.mg.gov.br/bolsa-verde>. Acesso em: 04 set. 2010.

MACHADO, Paulo Affonso Leme. Direito ambiental brasileiro. 14. ed. São Paulo: Malheiros, 2006. 1094 p.

MILARÉ, Édis. Direito do ambiente: doutrina, jurisprudência, glossário. 4. ed. São Paulo: Revista dos Tribunais, 2005, 1119 p.

MINAS GERAIS. Secretaria de Estado de Meio Ambiente e Desenvolvimento Sustentável. ICMS Ecológico. Disponível em: <http:// www.semad.mg.gov.br/icms-ecologico>. Acesso em: 25 out. 2010 .

. Lei Estadual n. ${ }^{\circ} 17.727$ de 13 de agosto

de 2008. Dispõe sobre a concessão de incentivo financeiro a proprietários e posseiros rurais, sob a denominação de Bolsa Verde, para os fins que 
especifica, e altera as leis n. ${ }^{\text {os }} 13.199$, de 29 de janeiro de 1999, que dispõe sobre a Política Estadual dos Recursos Hídricos, e 14.309, de 19 de junho de 2002, que dispõe sobre as Políticas Florestal e de Proteção à biodiversidade no Estado. Assembleia Legislativa do Estado de Minas Gerais, Belo Horizonte, MG Disponível em: <http:// www.almg.gov.brindex.asp?grupo=legislacao\& diretorio=njmg\&arquivo=legislacao_mineira> . Acesso em: 25 out. 2010.

PAIM, Maurício Carneiro. Conservação da Mata
Atlântica: novos desafios do direito ambiental.

\section{Revista AGIR de Ambiente e}

Sustentabilidades, Ibirapitinga, v.2, n.1, p.100, dez/mar. 2010.

SOUZA, Daniela Noleto de. ICMS

ECOLÓGICO - Incentivo Fiscal para a Classe Empresarial. Disponível em: <http:// www.administradores.com.br/ informe-se/ artigos/icms-ecologico-incentivo-fiscal-paraclasse-empresarial/45614/print/> . Acesso em: 15 out. 2010.

RECEBIDO EM 13/10/2010

Асегто ем 2/12/2010 